honourable position in our curriculum. At other schools, as, for example, the Manchester Grammar School, I am told that even a larger proportion of the time of the boys is given to work of this kind ; and on the whole I am inclined to think that, notwithstanding the reluctance of some of the old foundations to admit the interloper, yet that the prospects of science in connection with general education are exceedingly satisfactory and encouraging.

It would be a mistake to attempt to displace classical studies, as some people seem to wish, in favour of science or any other subject. It cannot be expected that all boys should have the same tastes or capabilities. It would be as much an error to compel a boy, who has shown no aptitude for science, to devote any large proportion of his time to that subject, when he might be getting on with his classics, as it would be to doom another to Latin prose when his heart was all the time in the laboratory. The true system I believe to be this. After passing through a junior school, in which all should be equally instructed in some branch of natural history or experimental science, boys should then be drafted off into one of three departments. There should be (1) a classical school, in which Latin and Greek should be the staple, though not to the exclusion of a certain modicum of mathematics and science ; (2) a modern school, in which mathematics are predominant; and (3) a science school, in which languages, though subordinate to science, should not be altogether extinguished. This is very nearly the system pursued at Clifton, and I can testify to its practical convenience and success.

As regards the choice of subjects, though $I$ believe chemistry is pre-eminent in its capacity for developing certain of the mental powers, I consider that the fullest advantage is not derived from it, unless it is taught in a certain way. I hold that teachers of chemistry in schools are wiong when they set about teaching boys according to the methods commonly in use in the instruction of ordinary chemical students. The latter have to apply their knowledge to practical purposes, and this is not the prime object to be kept in view in determining the educational value of a given subject.

And this leads me back to the question of examination papers. I consider that examiners have as much to learn as teachers in connection with their respective functions. At present it is too frequently, "How do you make this ?" or, "What are the properties of that ?" a style of question which is good enough in its way, but to answer requires very little intellectual effort. The preparation for such an examination is little better than "cram," and is of proportionately small educational value.

If examiners, whether in school or university, would take more pains in framing their questions so as to extract not alone that which is in the memory of the candidate, but to get the product of his brain, I believe great and important service would be rendered to scientific education.

William A. TILDEN

Clifton College, Bristol, March 6

\section{PRINCIPAL CHARACTERS OF THE DINOCERATA}

UNDER the above title, Prof. O.C. Marsh, of Yale College, has published several facts of great importance with reference to the structure of the huge Eocene Mammals of Wyoming, of which we have already given a short description (NATURE, vol. vii. p. 366) from the same author's memoirs.

We now learn that the brain as known from the inside of the skull was very remarkable, being proportionately smaller than in any other known mammal, the Spermaceti and some other whales alone excepted. In Dinoceras mirabilis the entire brain was not greater in any of its transverse dimensions than the spinal canal in the cervical region. Its relative size and position can be best estimated from the accompanying drawing, copied from one given by Prof. Marsh, the brain in it being shaded, with a portion of the spinal cord attached. From the figure it is also evident that the olfactory lobes are proportionately large, at the same time that the cerebral lobes are hardly bigger than in some reptiles. The cerebellum must also have been small, whilst the cranial as well as the spinal nerves and the cord were immense.

The teeth are figured with their prominent $V$ shaped ridges, the dental formula being given as :$i \frac{0}{3} c \frac{x}{x} p m \frac{3}{3} m \frac{3}{3} \times 2=34$. The uppercanines were very long and pointed, and peculiar expanded descending processes on either side of the lower jaw seem to have acted as guards to protect them whilst the mouth was closed. The condyles of the lower jaw were transverse, and therefore only

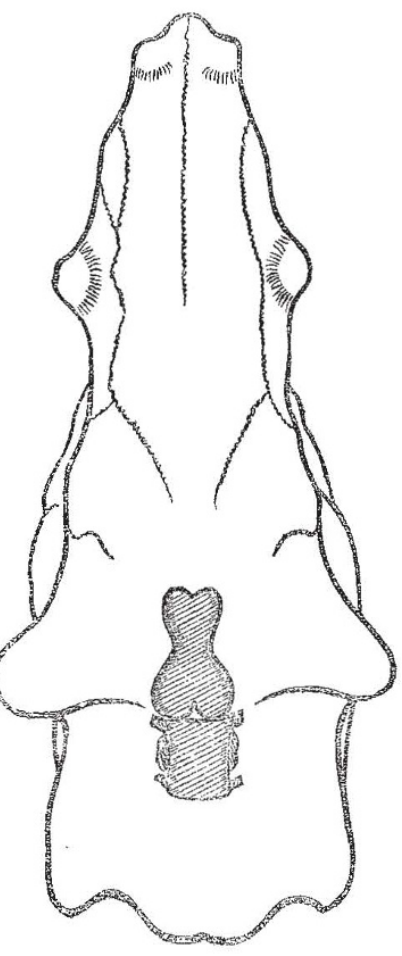
allowed of an up-and.

down movement. The molars were peculiarly smail for the size of the animal and of the skull. The creature must have been carnivorous, as mastication could only have been slight, and the food therefore nutritious.

The feet are figured. They were very elephantine, there being five digits on each; these, with the carpus and tarsus, being short and compressed from above downwards. The terminal phalanges were well developed. The other bones much reserabled those of the elephant in size as well as contour. Prof. Marsh tells us that the head could evidently reach the ground, and that there is no evidence of a proboscis.

These characters all point to the fact that in Eocene times there lived an order of animals which have no representatives at the present day, and that they were highly specialised in some points of their structure, whilst in others they were equally ill.developed.

\section{NOTES}

WE learn that a scheme is on foot for a memorial of the late Prof. Rankine. Students of Thermodynamics, Engineering, \&c.s will be doubly delighted to hear that the memorial is to take the form of an edition, in two handsome quarto volumes, of his valuable papers contributed to the various scientific societies and magazines.

A SRRIES of lectures upon zoological subjects will be delivered after Easter in the Zoological Society's Gardens, in Regent's Park, on Thursdays, at 5 P.M. The following are the titles, together with the days on which they will be delivered by the respective lecturers :-A pril 27, Mr. P. L. Sclater, F.R.S., on the Society's Gardens and their inhabitants; May 4, Prof. Flower, F.R.S., Rhinoceroses and Tapirs; May II, Prof. Flower, Horses and Zebras; May 18, Dr. J. Murie, the Manatee; May 25, Prof. Garrod, On Birds ; June I, Prof. Mivart, On Bats; June 8, Mr. Tegetmeier, On Homing Pigeons; 